\title{
Transcriptional Remodeling in Response to Iron Deprivation in Saccharomyces cerevisiae
}

\author{
Minoo Shakoury-Elizeh, ${ }^{*}$ John Tiedeman, ${ }^{*+}$ Jared Rashford, ${ }^{* \neq}$ \\ Tracey Ferea, ${ }^{\S}$ Janos Demeter, ${ }^{\S}$ Emily Garcia, ${ }^{\text {II }}$ Ronda Rolfes, ${ }^{\text {II }}$ \\ Patrick O. Brown, ${ }^{* *}$ David Botstein, ${ }^{++}$and Caroline C. Philpott ${ }^{*+\ddagger}$
}

\author{
* Liver Diseases Section, National Institute of Diabetes and Digestive and Kidney Diseases, National \\ Institutes of Health, Bethesda, Maryland 20892; and \$Department of Genetics, Stanford University, \\ Stanford, California 94305
}

Submitted September 4, 2003; Revised October 15, 2003; Accepted October 20, 2003

Monitoring Editor: Trisha Davis

\begin{abstract}
The budding yeast Saccharomyces cerevisiae responds to depletion of iron in the environment by activating Aft1p, the major iron-dependent transcription factor, and by transcribing systems involved in the uptake of iron. Here, we have studied the transcriptional response to iron deprivation and have identified new Aft1p target genes. We find that other metabolic pathways are regulated by iron: biotin uptake and biosynthesis, nitrogen assimilation, and purine biosynthesis. Two enzymes active in these pathways, biotin synthase and glutamate synthase, require an iron-sulfur cluster for activity. Iron deprivation activates transcription of the biotin importer and simultaneously represses transcription of the entire biotin biosynthetic pathway. Multiple genes involved in nitrogen assimilation and amino acid metabolism are induced by iron deprivation, whereas glutamate synthase, a key enzyme in nitrogen assimilation, is repressed. A CGG palindrome within the promoter of glutamate synthase confers iron-regulated expression, suggesting control by a transcription factor of the binuclear zinc cluster family. We provide evidence that yeast subjected to iron deprivation undergo a transcriptional remodeling, resulting in a shift from iron-dependent to parallel, but iron-independent, metabolic pathways.
\end{abstract}

\section{INTRODUCTION}

Iron is an essential nutrient for virtually every organism on earth, because iron participates as a cofactor in numerous essential enzymatic reactions involving the transfer of electrons. Remarkably, organisms can thrive in environments in which the bioavailable iron is extremely scarce, and they can survive tremendous changes in environmental iron conditions, in part by altering patterns of transcription. The budding yeast Saccharomyces cerevisiae responds to depletion of iron in the environment by increasing the expression of systems involved in the uptake of iron. Other metabolic alterations that might occur in response to iron deprivation and the controls for any such alterations are not known. These systems of iron uptake are controlled primarily by Aft1p, the major iron-dependent transcription factor in yeast

Article published online ahead of print. Mol. Biol. Cell 10.1091/ mbc.E03-09-0642. Article and publication date are available at www.molbiolcell.org/cgi/doi/10.1091/mbc.E03-09-0642.

$\square$ Online version of this article contains supplementary material for some figures. Online version available at www.molbiolcell. org.

Present addresses: 'University of Virginia School of Medicine, Charlottesville, VA; ${ }^{\ddagger}$ Roswell High School, Roswell, GA; ${ }^{\circledR}$ Department of Genetics, Stanford University, Stanford, CA; "Applied Biosystems, Foster City, CA; IIDepartment of Biology, Georgetown University, Washington, DC; "Department of Molecular, Cellular, and Developmental Biology, University of California, Santa Barbara, Santa Barbara, CA; ${ }^{* *}$ Department of Biochemistry, Stanford University, Stanford, CA; ${ }^{++}$Institute for Integrative Genomics, Princeton University, Princeton, NJ.

¥ Corresponding author. E-mail address: carolinep@intra.niddk. nih.gov.
(Yamaguchi-Iwai et al., 1995). Aft1p is constitutively expressed in the cytosol of growing cells, and iron depletion triggers a relocalization of Aft1p to the nucleus, where it binds DNA and activates transcription (Yamaguchi-Iwai et al., 2002). A related transcription factor, Aft $2 p$, regulates a subset of the Aft1p target genes, but the role of Aft $2 p$ in iron homeostasis is less clear (Blaiseau et al., 2001; Rutherford et al., 2001, 2003).

Aft1p activates the transcription of a set of 17 genes involved in the reductive and nonreductive uptake of iron salts and iron-siderophore chelates into the cell. This set includes three cell wall mannoproteins, Fit1p, Fit2p, and Fit $3 p$, which are involved in the retention of iron in the cell wall and enhance the uptake of siderophore-bound iron (Protchenko et al., 2001). The reductive system of uptake begins with the reduction of ferric iron salts and chelates to the ferrous form by members of the FRE family of plasma membrane metalloreductases Fre1p, Fre2p, Fre3p, and Fre4p (Dancis et al., 1990; Georgatsou and Alexandraki, 1994; Yun et al., 2001). Two additional FRE family members, Fre5p and Fre6p, are regulated by Aft1p but are not yet functionally characterized, and a seventh family member, Fre7p, is regulated by copper (Martins et al., 1998). Reduced iron is then taken up by the high-affinity ferrous transport complex composed of the multicopper oxidase, Fet3p (Askwith et al. 1994), and the iron permease, Ftr1p (Stearman et al., 1996). Intracellular copper loading of Fet3p occurs through the activities of the copper chaperone Atx1p (Lin et al., 1997) and the microsomal copper transporter Ccc2p (Yuan et al., 1995). A second, nonreductive system of iron uptake exhibits specificity for a variety of siderophore-iron chelates and is composed of four transporters encoded by ARN1, ARN2/TAF1, 
ARN3/SIT1, and ARN4/ENB1 (Heymann et al., 1999, 2000a,b; Lesuisse et al., 1998; Yun et al., 2000a,b).

These Aft1p target genes involved in iron uptake have been identified both through traditional yeast genetic methods and through cDNA microarrays representing the entire yeast genome. Microarrays designed to identify genes that were differentially expressed after deletion of YFH1 (Foury and Talibi, 2001), a gene involved in mitochondrial ironsulfur cluster metabolism, and arrays designed to identify genes differentially regulated by cobalt stress (Stadler and Schweyen, 2002) identified a number of Aft1p target genes. Some genes that were differentially expressed in these arrays were also noted to have Aft1p consensus binding sites in their promoter regions, but these genes were not definitively shown to be Aftlp target genes. Arrays designed to identify genes expressed in the presence of a constitutively active AFT1 or AFT2 allele also identified many Aft1p target genes (Rutherford et al., 2003) but did not distinguish between direct and indirect effects of Aft1p expression. Here, we describe the transcriptional response to iron deprivation in yeast and identify both the set of genes directly regulated by Aft1p and genes that are regulated in response to changes in iron availability independently of Aft1p. We report that Aft1p also directs the transcription of genes involved in intracellular iron utilization and homeostasis and that the biotin, glutamate, and purine biosynthetic pathways are transcriptionally regulated in response to changes in iron availability. Promoter mapping data indicate that a transcription factor of the binuclear zinc cluster family may activate transcription under conditions of iron sufficiency.

\section{MATERIALS AND METHODS}

\section{Yeast Strains, Plasmids, and Media}

Strain DBY7286 (MATa ura3 GAL) and the congenic aft1 mutants were used for cDNA microarrays, Northern blots, and enzymatic assays (Yun et al., 2000a). To generate the vht1 $\Delta$ strain, the strain RG24695 (MATa/ $\alpha$ his $3 \Delta 1$ )

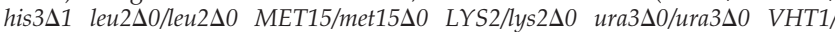
vht1 $\Delta: K A N$; Research Genetics, Huntsville, AL) was sporulated and the spore clones allowed to germinate on YPD medium supplemented with biotin 100 $\mathrm{ng} / \mathrm{ml}$. A tetrad containing two clones that failed to grow on SC medium but grew on medium containing biotin and geneticin $(v h t 1 \Delta)$ and two clones that grew on SC medium but failed to grow in the presence of geneticin $(V H T 1+)$ was used in biotin/KAPA growth experiments. To construct the aft $1 \Delta$ strain in the constitutively active Fet3p/Ftr1p background, the plasmid YIpDCE1/ FET3-HA/FTR1-MYC was linearized and integrated at the ADE2 locus of the strain CPY101 (MATa ura3-52 lys2-801(amber) ade2-101(ochre) trp1- 63 his3$\Delta 200$ leu2- $\Delta 1$, aft1::TRP1) (Philpott et al., 1998) and the congenic parent strain YPH499 as described previously (Stearman et al., 1998).

Plasmids 1-6, containing the GLT1 promoter regions including the GLT1 translation start codon fused to lacZ, were constructed by polymerase chain reaction (PCR) by using primers containing an XhoI site in the forward primer and a BamHI site in the reverse primer. PCR products were cloned into pLG699-Z (Guarente and Ptashne, 1981) that had been linearized with XhoI and BamHI. Plasmids 7-9 and 11-14 were constructed from PCR fragments containing XhoI sites at both ends, which were cloned into the XhoI site of plasmid 5. Plasmid 10 was constructed by cloning the PCR fragment into plasmid 6. All constructs were confirmed by sequencing. YPD medium, SD medium, and defined-iron medium were prepared as described previously (Philpott et al., 1998; Sherman, 1991). Defined-iron medium contains $1 \mathrm{mM}$ ferrozine, a ferrous iron chelator that, in the presence of ferrous iron salts, produces a medium containing a constant and reproducible amount of free ferrous iron.

\section{cDNA Microarrays}

Strains were grown to mid-log phase $\left(\mathrm{A}_{600}\right.$ of $\left.0.4-0.6\right)$ in either SD medium containing complete supplemental mixture $(0.8 \mathrm{~g} / 1)$ or defined iron medium (also contains complete supplemental mixture) containing $20 \mu \mathrm{M}$ (iron-poor), $100 \mu \mathrm{M}$ (iron-sufficient), or $500 \mu \mathrm{M}$ (iron-enriched) ferrous ammonium sulfate. Total RNA was isolated using TRIzol (Invitrogen, Carlsbad, CA) according to the manufacturer's instructions. Probe preparation, microarray production, hybridization, and data acquisition were performed as described previously (DeRisi et al., 1997). Probes generated from the AFT1-1 ${ }^{u p}$ strain, cells grown in iron-poor medium, and cells grown in iron-enriched medium were labeled with Cy5 (red), and probes generated from the wild-type strain, the aft $1 \Delta$ strain, and cells grown in iron-sufficient medium were labeled with Cy3 (green). Data were analyzed using ScanAlyze software (available at http://rana.lbl.gov/EisenSoftware.htm). Each array was performed twice using probes generated from independent cultures grown on different days. The AFT1- $1^{u p}$ array was performed once in comparison with the wild-type strain and once in comparison with the aft $1 \Delta$ strain with similar results, because Aft1p-dependent transcription is repressed in SD medium (Yun et al., 2000a). The complete data set for the arrays is available at http://genomewww.stanford.edu/microarray.

\section{Northern Blot Analysis and Biotin Growth Assay}

RNA isolation and Northern blot analysis were performed as described previously (Philpott et al., 1998) by using ${ }^{32} \mathrm{P}-$ labeled probes that correspond to the entire open reading frames of the indicated genes. For growth assays, strains were precultured in either SC medium or defined-iron medium containing $5 \mu \mathrm{M}$ ferrous ammonium sulfate and then inoculated into the same medium containing 7-keto, 8-amino pelargonic acid (KAPA; gift of Claude Alban, Aventis, Strasbourg, France) at $0,1,5$, or $10 \mathrm{ng} / \mathrm{ml}$ or biotin at 100 $\mathrm{ng} / \mathrm{ml}$ and grown at $30^{\circ} \mathrm{C}$ with shaking. Samples were withdrawn periodically and the $\mathrm{A}_{600}$ determined.

\section{Enzymatic Assays}

Glutamate dehydrogenase activity was measured spectrophotometrically at $23^{\circ} \mathrm{C}$ by the oxidation of the reduced coenzyme NADPH as described previously (Doherty, 1970). Glutamine synthetase activity was measured at $30^{\circ} \mathrm{C}$ by the transferase reaction as described previously (Mitchell and Magasanik, 1983). Glutamate synthase activity was measured at $23^{\circ} \mathrm{C}$ by the oxidation of NADH as described previously (Roon et al., 1974). $\beta$-Galactosidase activity was measured by the production of $o$-nitrophenol at $28^{\circ} \mathrm{C}$ as described previously (Adams et al., 1997).

\section{RESULTS}

The Iron- and Aft1p-dependent Transcriptional Response

To define the set of genes that was directly regulated by Aft1p, we used cDNA microarrays to identify genes that exhibited increased expression in iron-poor medium, decreased expression in iron-enriched medium, or increased expression in a strain expressing AFT1- ${ }^{u p}$, a constitutively active allele of AFT1 (Yamaguchi-Iwai et al., 1995). Expression of AFT1-1 up results in high levels of transcription of Aft1p target genes, regardless of the amount of iron in the medium. For each of the identified genes, we examined the upstream DNA sequences within 700 base pairs of the open reading frame for the Aft1p consensus binding site, (T/C)(G/A)CACCC (Yamaguchi-Iwai et al., 1996). Genes that exhibited this pattern of iron and Aft1p regulation and also contained an Aft1p consensus site were further examined by Northern blot analysis and were confirmed as Aft1p target genes if they exhibited increased expression in both the AFT1- $1^{u p}$ strain and in iron-poor medium. By identifying only those genes that were activated in both of these conditions, we were able to exclude genes that were indirectly activated by iron deprivation in the wild-type strain or by iron accumulation in the AFT1-1 ${ }^{u p}$ strain. Examination of the entire yeast genome for Aft $1 \mathrm{p}$ consensus sites by using multiple EM for motif elicitation revealed that many genes that were not regulated by iron or Aft1p contained this minimal binding site in the upstream region (T.F. and C.C.P., unpublished observations). This finding indicated that the presence of an Aft1p site could not be used as the sole criterion to identify the Aft1p regulon. The set of genes regulated by Aft1p, including target genes identified in previous studies, is presented in Figure 1 . A clustered analysis of all of the genes exhibiting iron- and Aft1p-dependent regulation is presented in Supplementary Figure 1.

In addition to the 17 genes involved in the uptake of iron at the plasma membrane and FTH1, a gene involved in vacuolar iron transport (Urbanowski and Piper, 1999), we identified TIS11, a gene of unknown function; HMX1, which has homology to heme oxygenases; and three additional 


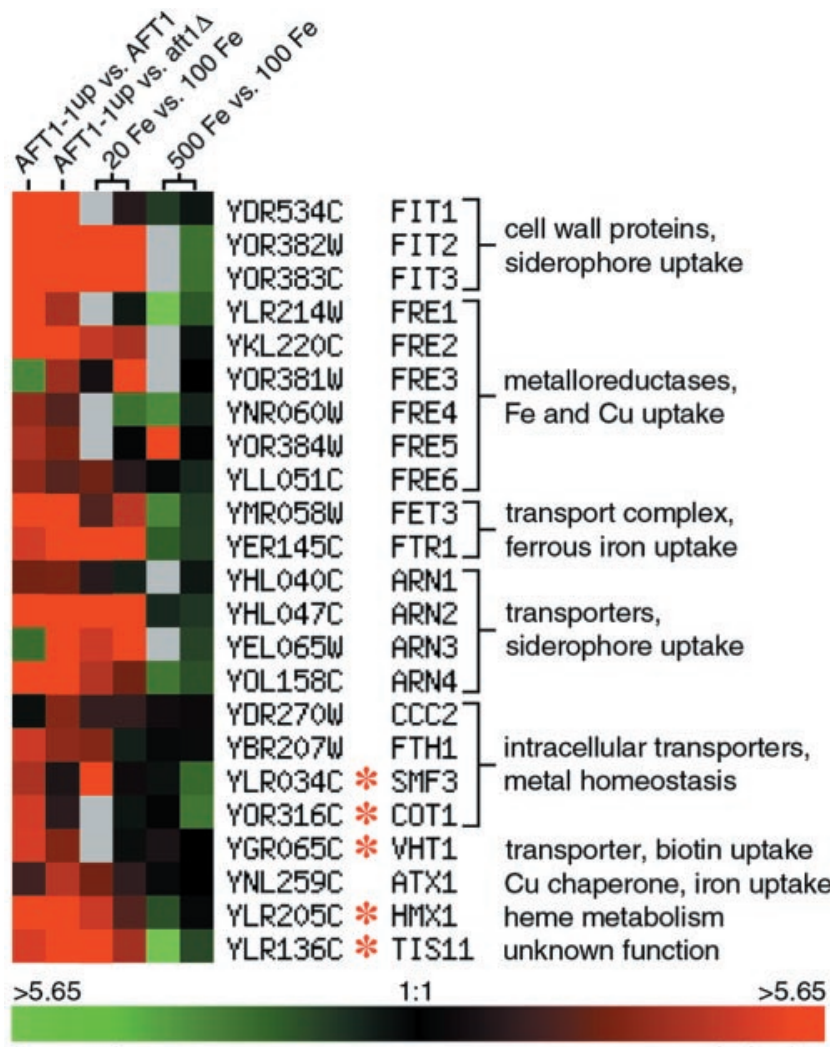

Repression

Induction

Figure 1. Relative mRNA levels of Aft1p target genes by cDNA microarray analysis. Aft1p target genes identified in previous studies and in this study are shown. Aft1p target genes described in this article are marked with an asterisk. Each column represents a single array and each cell represents the ratio of the mRNA levels from the first culture condition to the second culture condition. Transcripts more highly expressed in the first culture are in red, transcripts more highly expressed in the second culture are in green. The scale indicates the magnitude of the expression ratio. Gray cells indicate a missing data point. Genes were grouped according to their functional role in iron metabolism. The complete data set for the microarrays is available at http:/ / microarray-pubs.stanford.edu/iron_reg/index.shtml. A clustered analysis of all of the genes exhibiting iron- and Aft1p-dependent regulation is presented in Supplementary Figure 1.

transporters, SMF3, COT1, and VHT1. TIS11 and HMX1 each exhibited multiple Aft1p consensus binding sites in the upstream sequences of the DNA, whereas SMF3, COT1, and VHT1 each exhibited a single consensus binding site for Aft1p in the $5^{\prime}$ region of the gene (Figure 2A). The transcription profile for each of these genes was similar, with higher mRNA levels present in cells grown in iron-poor medium and in the AFT1-1 ${ }^{\text {up }}$ strain, suggesting that each of these genes was a direct target of Aft1p (Figure 2B). Transcript levels for SMF3, COT1, and VHT1 were low, but readily detectable, in cells grown in iron-sufficient medium and in an AFT1-deleted strain, indicating that these genes were also under the control of other transcription factors and may have a role outside the response to iron deprivation. SMF3 mRNA levels increased only slightly in the AFT1-1 ${ }^{\text {up }}$ strain, indicating that much of the iron-dependent regulation occurred through another transcription factor, such as Aft2p (Portnoy et al., 2002; Rutherford et al., 2003).

The newly described Aft1p target genes that have been characterized, along with FTH1, function in the mobilization
A

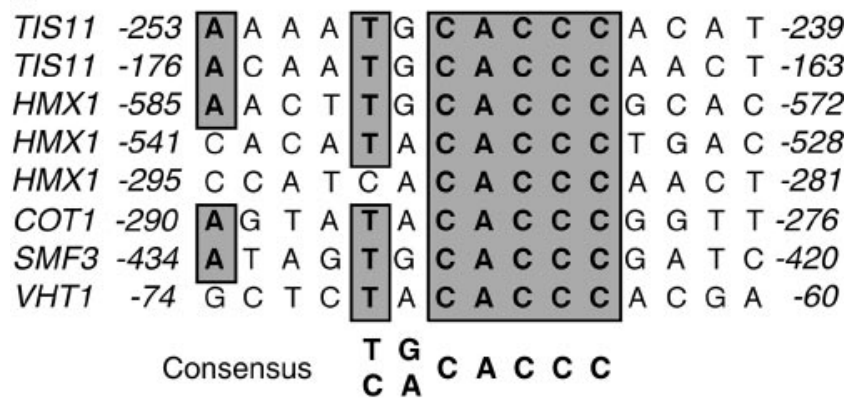

B

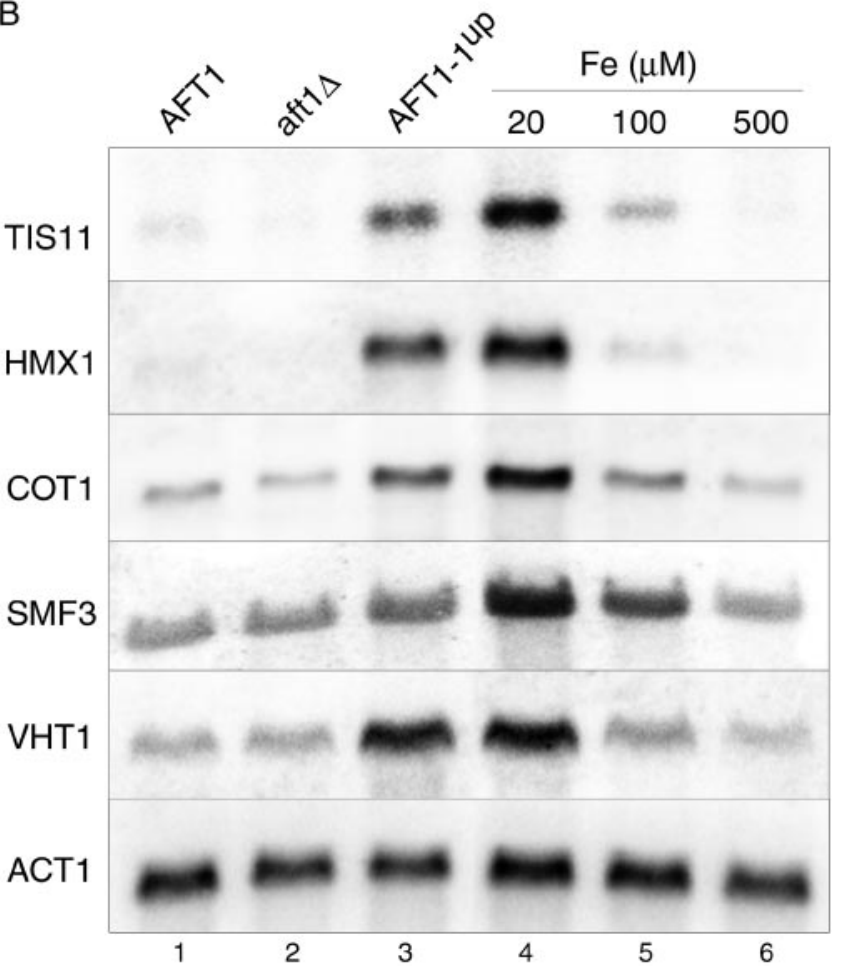

Figure 2. Iron- and Aft1p-dependent transcription of new genes in the Aft1p regulon. (A) Consensus binding sites for Aft1p in the DNA sequences upstream of TIS11, HMX1, COT1, SMF3, and VHT1. Boxed and shaded nucleotides were identical in more than four of the eight sequences. Numbering corresponds to +1 at the putative translation start site. (B) Northern blot analysis of Aft1p regulated genes. Congenic $A F T 1+$, aft1 $\triangle$, and $A F T 1-1^{u p}$ strains were grown in SD medium (lanes 1-3) or the AFT1+ strain was grown in iron-poor $(20 \mu \mathrm{M})$, iron-sufficient $(100 \mu \mathrm{M})$, or iron-enriched (500 $\mu \mathrm{M})$ medium (lanes 4-6). Total RNA was isolated from cells in the exponential phase of growth and subjected to Northern blot analysis using the indicated probes. The actin signal (ACT1) served as a loading control.

and reutilization of intracellular iron and in the sequestration of other metals. HMX1 encodes a protein with heme degradation activity that is important in heme iron utilization in yeast (Protchenko and Philpott, 2003). TIS11 encodes a protein of the $\mathrm{CCCH}$ Zn-finger family, which is represented in mammals, flies, and worms, as well as yeast (Ma and Herschman, 1995; Thompson et al., 1996). Cot1p is a transporter located in the vacuolar membrane implicated in cobalt resistance (Conklin et al., 1992) and in the accumulation of zinc ions in the vacuole (MacDiarmid et al., 2000). The role of Cot1p in the response to iron deprivation is not clear, 
but sequestration of other divalent metals ions in the vacuole may be important for cell survival when iron is scarce ( $\mathrm{Li}$ and Kaplan, 1998). Smf3p is $27 \%$ identical at the amino acid level to DMT1, a mammalian iron transporter, and it is also expressed in vacuolar membranes and may be involved in the mobilization of vacuolar stores of iron (Portnoy et al., 2000). VHT1 encodes the essential $\mathrm{H}^{+}$-biotin symporter and was a surprising addition to the Aft1p regulon (Stolz et al., 1999).

\section{Iron Regulation of Biotin Uptake and Synthesis}

$S$. cerevisiae is auxotrophic for biotin, an essential nutrient also known as vitamin $\mathrm{H}$, and strains bearing deletions of VHT1 are not viable unless supplemented with certain biotin precursors or high concentrations of biotin (Stolz et al., 1999). In higher plants, most fungi, and bacteria, biotin is synthesized from pimelic acid in five steps (Figure 3A). Although the genome of budding yeast does not encode the enzymes for the first two steps of synthesis, yeast can synthesize biotin from the precursors KAPA and 7,8-diamino pelargonic acid (DAPA) through the activities encoded by $B I O 3$, $B I O 4$, and $B I O 2$, respectively. BIO5 encodes a high-affinity transporter for KAPA and DAPA. BIO2 encodes biotin synthase, the rate-limiting step in biotin synthesis, and this protein requires a $4 \mathrm{Fe}-4 \mathrm{~S}$ cluster for activity (Marquet et al., 2001). The Aft1p-dependent increase in VHT1 transcription during growth in iron-poor medium suggested that yeast increased the uptake of biotin under conditions of iron deprivation. We questioned whether this increase in biotin uptake occurred in response to a decrease in biotin synthesis, and therefore examined whether yeast could synthesize biotin under conditions of iron deprivation.

We constructed a VHT1-deletion strain and measured the capacity of the biotin precursor KAPA to support growth of this strain and the congenic VHT1+ strain in iron-rich medium and iron-poor medium (Figure 3, B-E). The vht1s strain cannot take up biotin at the low concentrations present in standard media and does not grow in the absence of supplemental biotin precursors or high concentrations of biotin. As expected, in iron-rich medium, the VHT1+ strain grew well with or without KAPA supplementation (Figure $3 \mathrm{~B})$, whereas the vht1 $\Delta$ strain grew well only in the presence of KAPA supplementation, although only very small amounts of KAPA were required (Figure 3C). When the $V H T 1+$ strain was introduced to iron-poor medium, the cells again grew in the presence or absence of KAPA (Figure 3D). In contrast, when the vht1 $\Delta$ strain was introduced to iron-poor medium, KAPA supplementation failed to support growth, and the cells grew only in the presence of high amounts of biotin (Figure 3E). These data indicated that, under conditions of iron deprivation, yeast did not synthesize sufficient quantities of biotin from the precursor KAPA to support growth.

We considered two explanations for the failure of yeast to synthesize biotin under conditions of iron deprivation: 1) the yeast failed to incorporate iron-sulfur clusters into Bio2p, and thereby produced inactive enzyme; or 2) the enzymes involved in the biotin biosynthetic pathway were poorly expressed. By Northern blot analysis, mRNA levels for each of the genes in the biotin synthetic pathway were reduced in cells grown in iron-poor medium when compared with cells grown in iron-enriched medium, with transcripts of $\mathrm{BIO} 3$ and $\mathrm{BIO} 4$ being very low in iron-poor and iron-sufficient medium (Figure 3F). These results suggested that transcription of the genes involved in biotin synthesis was repressed when iron was scarce and that biotin uptake and synthesis were reciprocally regulated at the transcriptional level by
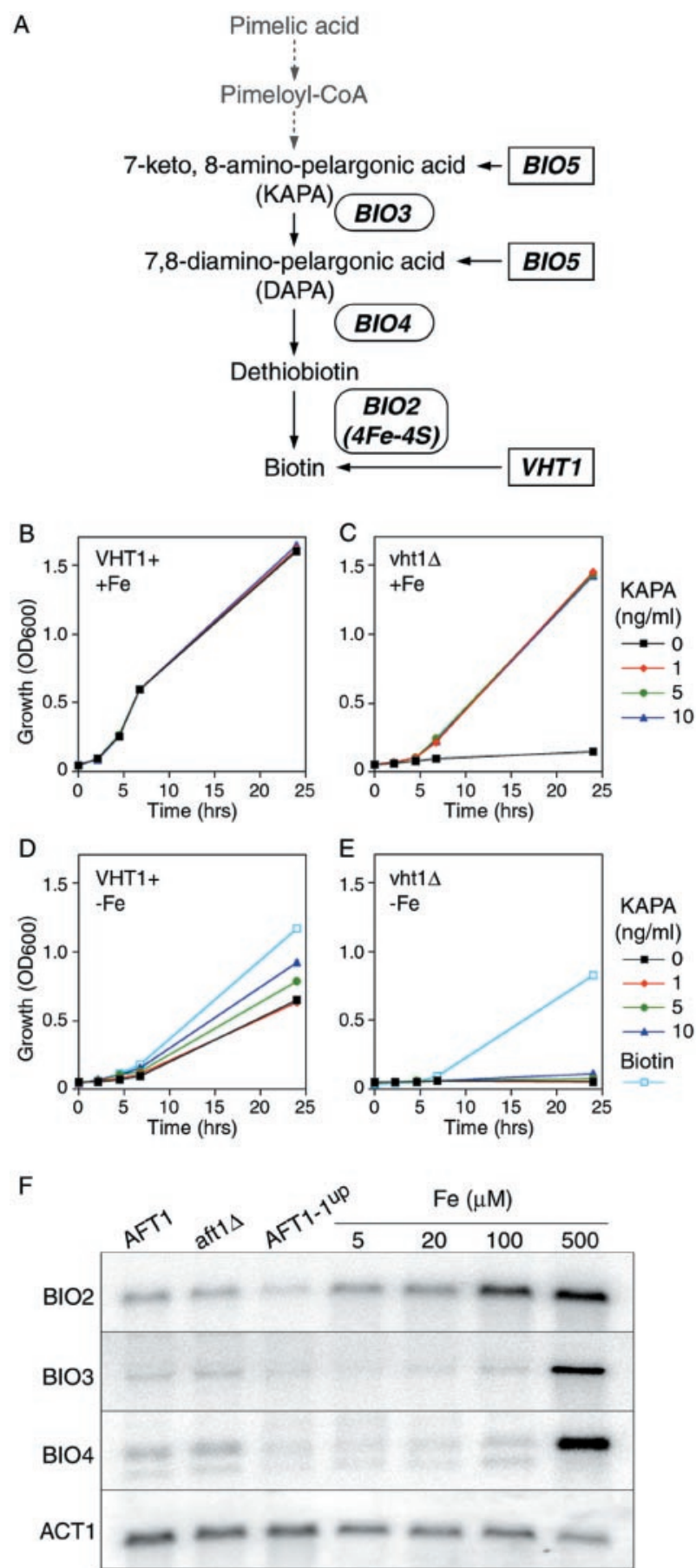

Figure 3. Failure of biotin synthesis under conditions of iron deprivation. (A) Biotin biosynthetic pathway in yeast. Genes in ovals encode enzymes of biotin biosynthetic pathway. Genes in boxes encode transporters of biotin or biotin precursors. Bio2p contains a $4 \mathrm{Fe}-4 \mathrm{~S}$ cluster. (B-E) Effect of iron deprivation on growth of cells synthesizing biotin de novo. The $V H T 1+(\mathrm{B}$ and $\mathrm{D})$ and the vht1D $(\mathrm{C}$ and $\mathrm{E})$ strains were precultured in $\mathrm{SD}$ $(+\mathrm{Fe}, \mathrm{B}$ and $\mathrm{C})$ medium or iron-poor medium $(-\mathrm{Fe}, \mathrm{D}$ and $\mathrm{E})$ and reinoculated at an $\mathrm{A}_{600}$ of 0.1 into the same medium containing the indicated amounts of KAPA or biotin at $100 \mathrm{ng} / \mathrm{ml}$. Aliquots of culture were removed at the indicated intervals and the absorbance at $600 \mathrm{~nm}$ was measured. (F) Iron-dependent transcription of $\mathrm{BIO} 2, \mathrm{BIO}$, and $\mathrm{BIO} 4$. Strains expressing the indicated AFT1 alleles were grown in SD medium and the $A F T 1+$ strain was grown in defined-iron medium supplemented with the indicated concentrations of iron. Total RNA was isolated from exponentially growing cells and Northern blot analysis was performed using the indicated probes. 
iron. $\mathrm{BIO} 2, \mathrm{BIO}$, and $\mathrm{BIO} 4$ may also be transcriptionally repressed when extracellular biotin levels rise (Stolz, personal communication). This could explain the reduced mRNA levels of these genes in the AFT1- $1^{\text {up }}$ strain, where increased expression of VHT1 would lead to increased biotin uptake. The small amount of KAPA-dependent growth observed in the iron-deficient cultures (Figure 3D) seems to be consistent with the small amount of BIO2, BIO3, and BIO4 transcription indicated by Northern blot analysis (Figure 3F).

\section{Regulation of Nitrogen Metabolism by Iron}

Further examination of the cDNA microarrays suggested that additional metabolic pathways might be regulated by iron. Twelve genes involved in the uptake and metabolism of amino acids and alternative nitrogen sources were more highly expressed in cells grown in iron-poor medium than in cells grown in iron-sufficient medium in at least one array (Figure 4A). Northern blot analysis confirmed that RNA levels for $M E P 2$, an ammonium transporter; $C A R 1$, an arginase; $A G P 1$, an asparagine and glutamine permease; and DUR3, a urea permease were elevated in cells grown in iron-poor medium compared with cells grown in either iron-sufficient or iron-enriched media (Figure 4B). None of these genes was more highly expressed in the AFT1-1 up strain by cDNA microarray or by Northern blot analysis, and, with the exception of CAR1, none contained an Aft1p consensus site, indicating that Aft1p did not directly regulate these genes. Further examination of the pathways of nitrogen assimilation suggested that the synthesis of glutamate and glutamine could account for this pattern of activation in iron-poor medium.

$S$. cerevisiae grows well when ammonium is provided as the sole source of nitrogen. To utilize ammonium, however, cells must first incorporate it into either glutamate or glutamine, because $\sim 88 \%$ of cellular nitrogen is derived from the amino group of glutamate and $12 \%$ is derived from the amide group of glutamine (Magasanik, 1992). The glutamate dehydrogenases encoded by GDH1 and GDH3 catalyze the NADPH-dependent formation of glutamate from ammonia and $\alpha$-ketoglutarate (Figure 5A, reaction 1 ). In reactions 2 and 3, glutamine synthetase, encoded by GLN1, catalyzes the formation of glutamine from ammonia and glutamate, and glutamate synthase, encoded by GLT1, catalyzes the formation of glutamate from glutamine and $\alpha$-ketoglutarate. The sum of reactions 2 and 3 is equivalent to reaction 1 , except that ATP is consumed and NADH substitutes for NADPH; therefore, reactions 2 and 3 represent an alternative pathway for the synthesis of glutamate. Glutamate synthases require a $4 \mathrm{Fe}-4 \mathrm{~S}$ cluster for activity (Curti et al., 1996), and we questioned whether the activity of these enzymes, especially Glt1p, might be affected by the availability of iron. Therefore, we grew cells in media containing varying amounts of iron and measured the activity of glutamate dehydrogenase, glutamine synthetase, and glutamate synthase in crude lysates (Figure 5B). Glutamate dehydrogenase and glutamine synthetase activities exhibited little change after growth in varying amounts of iron. In contrast, glutamate synthase activity was very low in lysates of cells grown in medium containing very low amounts of iron, but increased 20-fold as the concentration of iron in the medium increased.

The paucity of Glt1p activity after growth in iron-poor medium may reflect either a shortage of iron-sulfur clusters or a decrease in transcription. By Northern analysis, GLT1 mRNA levels decreased as the concentration of iron in the medium decreased (Figure 6A). Furthermore, all of the loss
A

$20 \mathrm{Fe}$ vs.

\begin{tabular}{lllc} 
100 Fe & Gene & Function & Induction \\
\hline & MEP2 & Ammonium transporter & 3.2 \\
GDH1 & Glutamate dehydrogenase & 2.7 \\
CAR1 & Arginase & 4.3 \\
GDH3 & Glutamate dehydrogenase & 1.3 \\
CHA1 & Threonine dehydratase & 1.6 \\
& AGP1 & Asparagine/glutamine permease & 2.6 \\
CAN1 & Basic amino acid permease & 2.1 \\
& GAT1 & Nitrogen regulatory factor & 1.5 \\
& ARO9 & Aromatic amino acid transferase & 1.9 \\
& DUR3 & Urea permease & 2.6 \\
& DAL3 & Ureidoglycolate hydrolase & 2.9 \\
& BAT2 & Branched amino acid transferase & 1.5 \\
\hline >5.65 & & & $>5.65$ \\
\hline
\end{tabular}

Repression

Induction

B

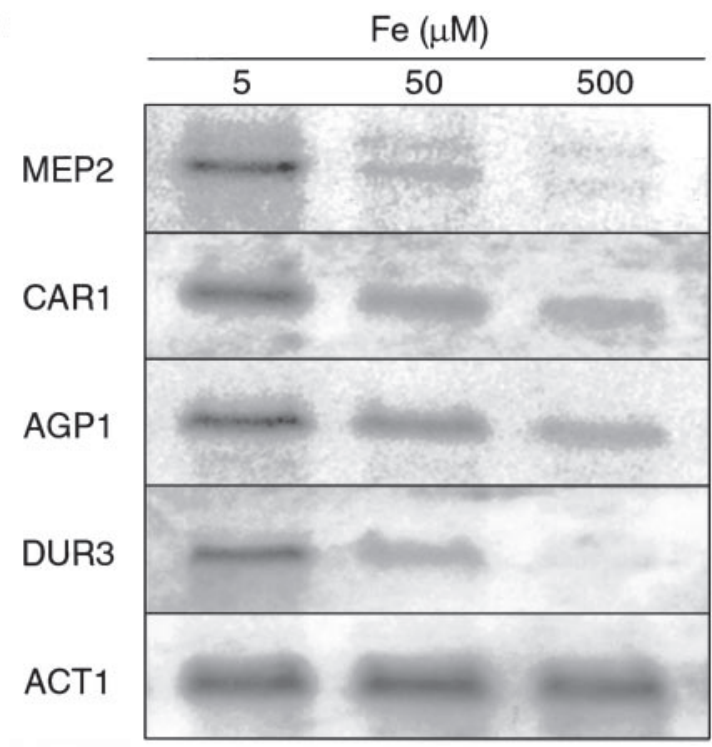

Figure 4. Transcriptional activation of genes involved in amino acid and nitrogen source uptake and metabolism under conditions of iron deprivation. (A) Microarray analysis. Data are presented from two arrays in which RNA from wild-type cells grown in iron-poor medium was compared with RNA from cells grown in iron-sufficient medium. A subset of genes with greater than twofold induction in at least one array is shown. The average induction in the two arrays is shown in the column on the right. (B) Northern blot analysis of a subset of the genes identified in $\mathrm{A}$.

of Glt1p activity in cells grown in decreasing amounts of iron could be explained by transcriptional repression of GLT1 under these growth conditions. These changes in GLT1 mRNA levels were not observed in the microarrays, possibly due to inefficient probe synthesis from an exceptionally long (>6 kbp) transcript. In contrast, GDH1, GDH3, and GLN1 mRNA levels changed in a complex manner when cells were grown in varying amounts of iron (Figure 6B). In cells grown in iron-sufficient or iron-enriched medium, transcription from GDH3 produced two species of mRNA. Cells grown in lower amounts of iron exhibited a loss of the smaller mRNA 
A 1. $\mathrm{NH}_{3}+\alpha$-ketoglutarate $+\mathrm{NADPH}+\mathrm{H}^{+} \stackrel{\mathrm{GDH} 3}{\longrightarrow}$ glutamate $+\mathrm{NADP}^{+}$

2. $\mathrm{NH}_{3}+$ glutamate + ATP $\stackrel{\text { GLN1 }}{\longrightarrow}$ glutamine + ADP glutamine $+\alpha$-ketoglutarate $+\mathrm{NADH}+\mathrm{H}^{+} \underset{4 \mathrm{Fe} 4 \mathrm{~S}}{\stackrel{\mathrm{GLT} 1}{\longrightarrow}} 2$ glutamate $+\mathrm{NAD}^{+}$

B
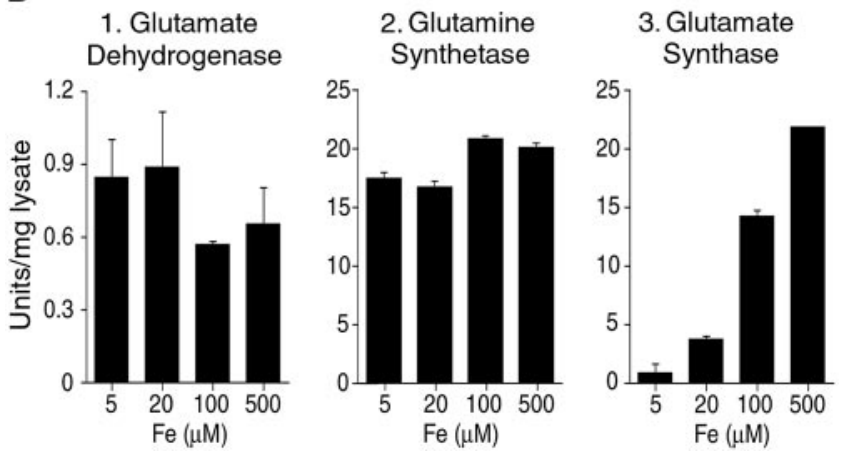

Figure 5. Effect of iron on glutamate biosynthesis. (A) Ammonia assimilation and glutamate synthesis in yeast. Genes encoding glutamate dehydrogenases (GDH1 and GDH3), glutamine synthetase (GLN1), and glutamate synthase (GLT1) and the reactions they catalyze are indicated. Glt1p is a $4 \mathrm{Fe}-4 \mathrm{~S}$ cluster protein. (B) Stimulation of glutamate synthase activity by iron supplementation. The parent strain was grown in defined-iron medium containing the indicated amounts of iron, crude cell lysates were prepared, and enzymatic activities were measured as described in MATERIALS AND METHODS. Assays were performed on duplicate samples, each assay was repeated twice, and the data were pooled for analysis. Error bars indicate the average deviation.

and the appearance of a third transcript that was more abundant and smaller than either of the first two transcripts. This third transcript was also present in cells expressing the AFT1-1 ${ }^{\text {up }}$ allele. The specificity of each of the detected transcripts for GDH3 was confirmed by Northern analysis of a GDH3-deletion strain (our unpublished data). GDH1 and GLN1 exhibited similar patterns of transcription, with mRNA levels increasing slightly in cells grown in iron-poor $(20 \mu \mathrm{M})$ medium, but not at the lowest iron concentrations. GLT1, GDH1, GDH3, and GLN1 are extensively regulated at the transcriptional level through multiple nitrogen-responsive transcription factors (Magasanik, 1992) but were not known to be regulated transcriptionally by iron.

Because Northern analysis indicated that transcription of GLT1 was repressed by iron deprivation and by expression of the AFT1-1 up allele, we considered whether Aft1p might also act as a transcriptional repressor. We therefore tested whether the iron-dependent regulation of GLT1 occurred in a strain deleted for AFT1. aft1D strains normally do not grow in media containing low amounts of iron due to a failure to express the high-affinity transport complex Fet3p/Ftr1p. To bypass this block on high-affinity iron uptake, we deleted AFT1 in a strain in which Fet3p and Ftr1p were expressed constitutively and measured the transcription of GLT1 in cells grown in varying amounts of iron (Figure 6C). No difference in the iron-dependent pattern of GLT1 expression was observed between the aft $1 \Delta$ strain and the congenic parent strain, indicating that Aft1p was not required for the iron-dependent transcription of GLT1. Subsequent rehybrid-
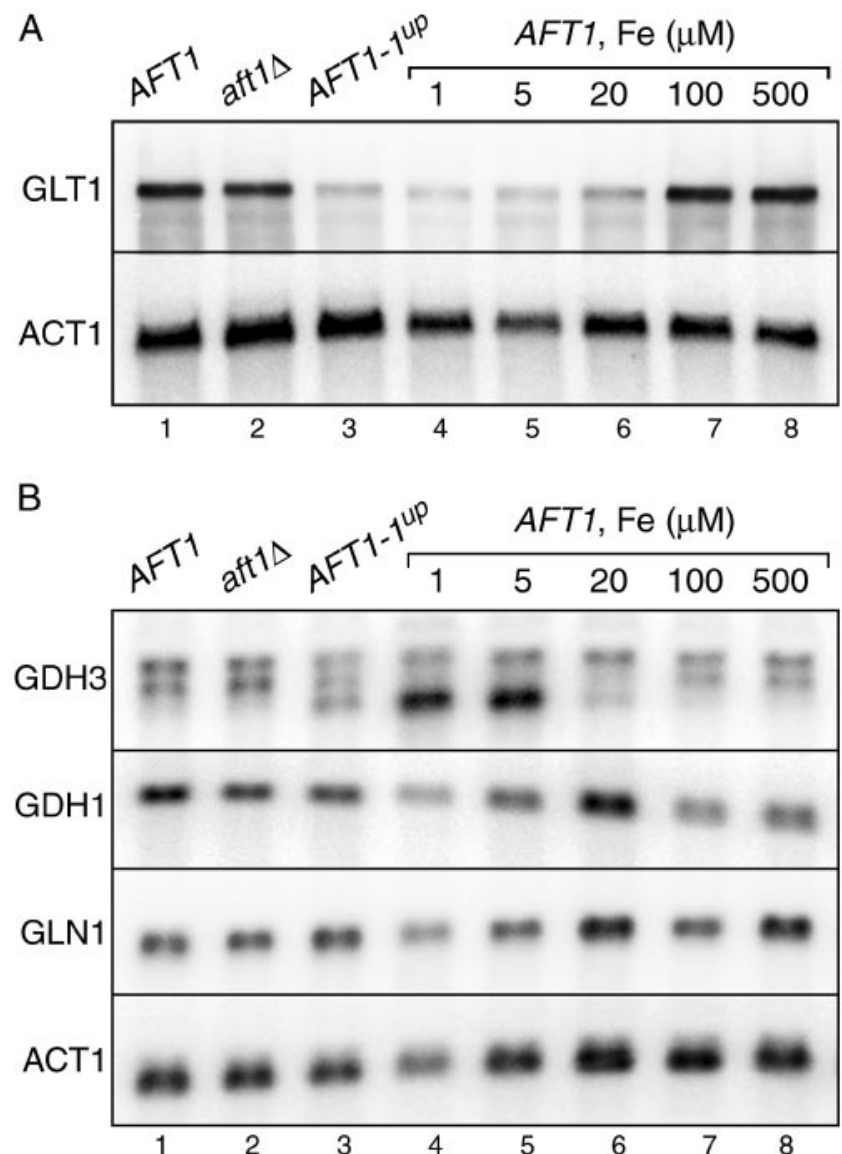

C

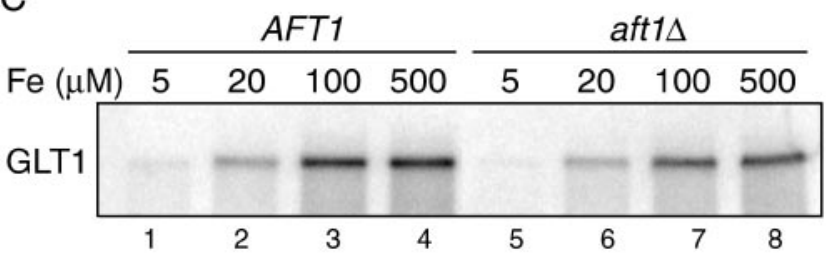

Figure 6. Activation of GLT1 transcription by iron supplementation. (A and B) Strains expressing the indicated AFT1 allele were grown in SD medium (lanes 1-3) or the AFT1+ strain was grown in defined-iron medium containing the indicated amounts of iron (lanes 4-8). Northern blot analysis was performed using probes for GLT1 (A), and GDH3, GDH1, and GLN1 (B). (C) Aft1p-independent activation of GLT1 transcription. A strain expressing the Fet3p/ Ftr1p iron transporter under the control of the constitutively active PGK1 promoter was deleted for AFT1. The resulting congenic $A F T 1+$ and aft $1 \Delta$ strains were grown in defined-iron medium containing the indicated amounts of iron and Northern blot analysis for GLT1 was performed.

ization with an ACT1 probe indicated equivalent RNA loading (our unpublished data).

\section{Iron Regulation of the Purine Biosynthetic Pathway}

Inspection of the cDNA microarrays comparing cells grown in iron-enriched medium to cells grown in iron-sufficient medium revealed that most of the genes involved in the biosynthesis of purines were induced when the concentration of iron was high (Figure 7A). These results were confirmed by Northern analysis of GCV1 and ADE17, which 
A $500 \mathrm{Fe}$ vs. $100 \mathrm{Fe}$

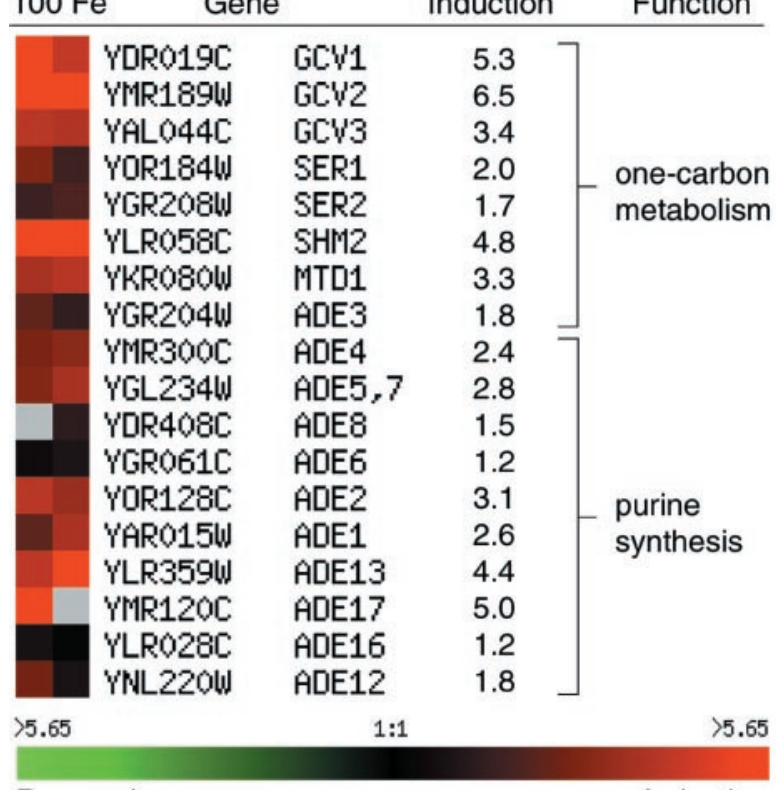

Repression

Induction

B

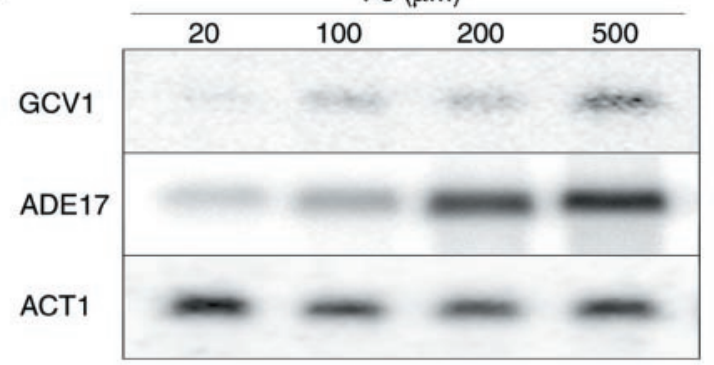

C
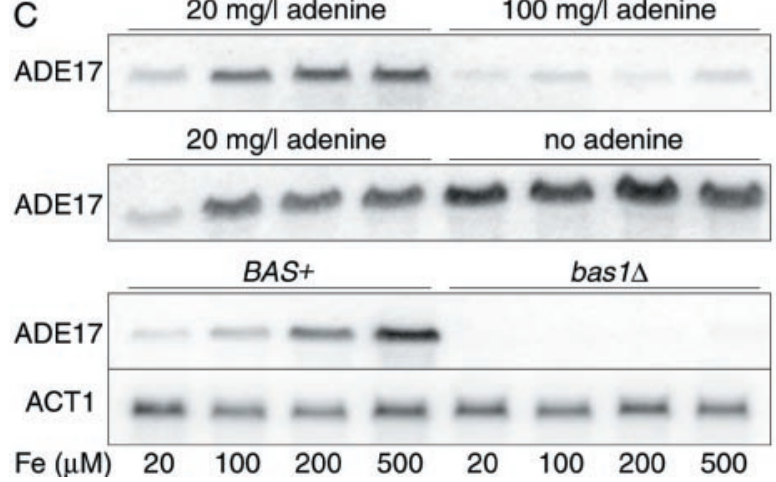

Figure 7. Transcriptional activation of the purine biosynthetic pathway by iron supplementation. (A) Microarray analysis. Data are presented from two arrays in which RNA from wild-type cells grown in ironenriched medium was compared with RNA from cells grown in ironsufficient medium. The sets of genes involved in one-carbon metabolism through folate and purine biosynthesis are shown. The average induction in the two arrays is indicated. (B) Northern blot confirmation of irondependent activation of purine biosynthetic pathway. Total RNA from wild-type cells grown in the indicated concentrations of iron was isolated, and Northern blot analysis was performed using probes for GCV1, $A D E 17$, and ACT1. (C) Role of adenine and Bas1p on iron-dependent activation of $A D E 17$. Northern blot analysis was performed on cells grown in the indicated concentrations of adenine and iron. BAS+ and bas1D strains were grown in $20 \mathrm{mg} / \mathrm{l}$ adenine. indicated that both genes were more highly expressed in cells grown in iron-enriched medium (Figure 7B). De novo synthesis of purines requires a succession of 10 enzymatic steps carried out by products of the $A D E$ genes. Glycine and one-carbon units produced by the glycine cleavage system and one-carbon metabolism through folate are also required for purine biosynthesis (Denis and Daignan-Fornier, 1998). These systems are coregulated by adenine through the transcription factors Bas1p and Bas2p (Daignan-Fornier and Fink, 1992). Adenine represses the transcription of the genes of purine biosynthesis and we examined whether iron affected this process. By Northern analysis, growth in media containing high amounts of adenine fully repressed $A D E 17$ transcription, even when iron concentrations were high (Figure 7C). Conversely, growth in media without adenine fully derepressed $A D E 17$ transcription, even when iron concentrations were low. Deletion of BAS1 also resulted in a near complete loss of ADE17 mRNA, with a concomitant loss of iron induction. These results suggested that the effect of iron on the expression of the purine biosynthetic pathway was indirect and might be mediated through the adenine-responsive Bas1p/Bas2p transcription factors.

Although bacterial and mammalian homologues of Ade4p require an iron-sulfur cluster for activity, in yeast, none of the enzymes involved directly in purine biosynthesis is known to require an iron-sulfur cluster (Mantsala and Zalkin, 1984). However, Gcv2p of the glycine cleavage system is a lipoylprotein, and lipoic acid synthase, encoded by LIP5, is an iron-sulfur cluster protein (OllagnierdeChoudens and Fontecave, 1999). Microarray data indicate that LIP5 mRNA levels were repressed 2.2-fold by growth in iron-poor medium, raising the possibility that the availability of lipoic acid may influence the expression of the purine biosynthetic pathway. Alternatively, the iron-dependent regulation may reflect the requirement of glutamine as a cosubstrate for purine biosynthesis, because approximately one-half of the glutamine produced by the cell is consumed through the synthesis of purine nucleotides (Magasanik, 1992). The available pools of glutamine may increase when growth in iron-poor medium leads to decreases in Glt1p activity, and increased flux through the purine biosynthetic pathway may be offset by lower levels of purine gene expression.

\section{Identification of an Iron-dependent Upstream Activation Sequence in GLT1}

To identify the sequences that conferred iron-dependent activation of transcription on GLT1 (the FeAS), 700 base pairs of the DNA sequence upstream of the open reading frame were fused to the lacZ reporter gene and introduced into the wild-type strain. We then measured $\beta$-galactosidase activity in cells grown in varying concentrations of iron, and found a 5.5-fold increase in activity as the iron concentration was increased from lowest to highest (Figure 8, plasmid 1). To further define the FeAS, a series of $5^{\prime}$ and $3^{\prime}$ deletions were made in the upstream sequences, fused to $l a c Z$, and tested. The sequences from -700 to -550 and from -450 to -260 were deleted without loss of iron-dependent activation, but deletion of the sequences from -550 to -450 resulted in a complete loss of activation (Figure 8, plasmids 2-9). Previous investigators had identified two putative TATA boxes in the GLT1 upstream DNA and shown that the 5'-most TATA box controls the preferred transcription start site (Valenzuela et al., 1998). Deletion of the region containing the 5'-most TATA box also resulted in a loss of iron-dependent activation (Figure 8, plasmid 10). Further deletions of the sequences between -550 and -450 indicated that a $44-$ 


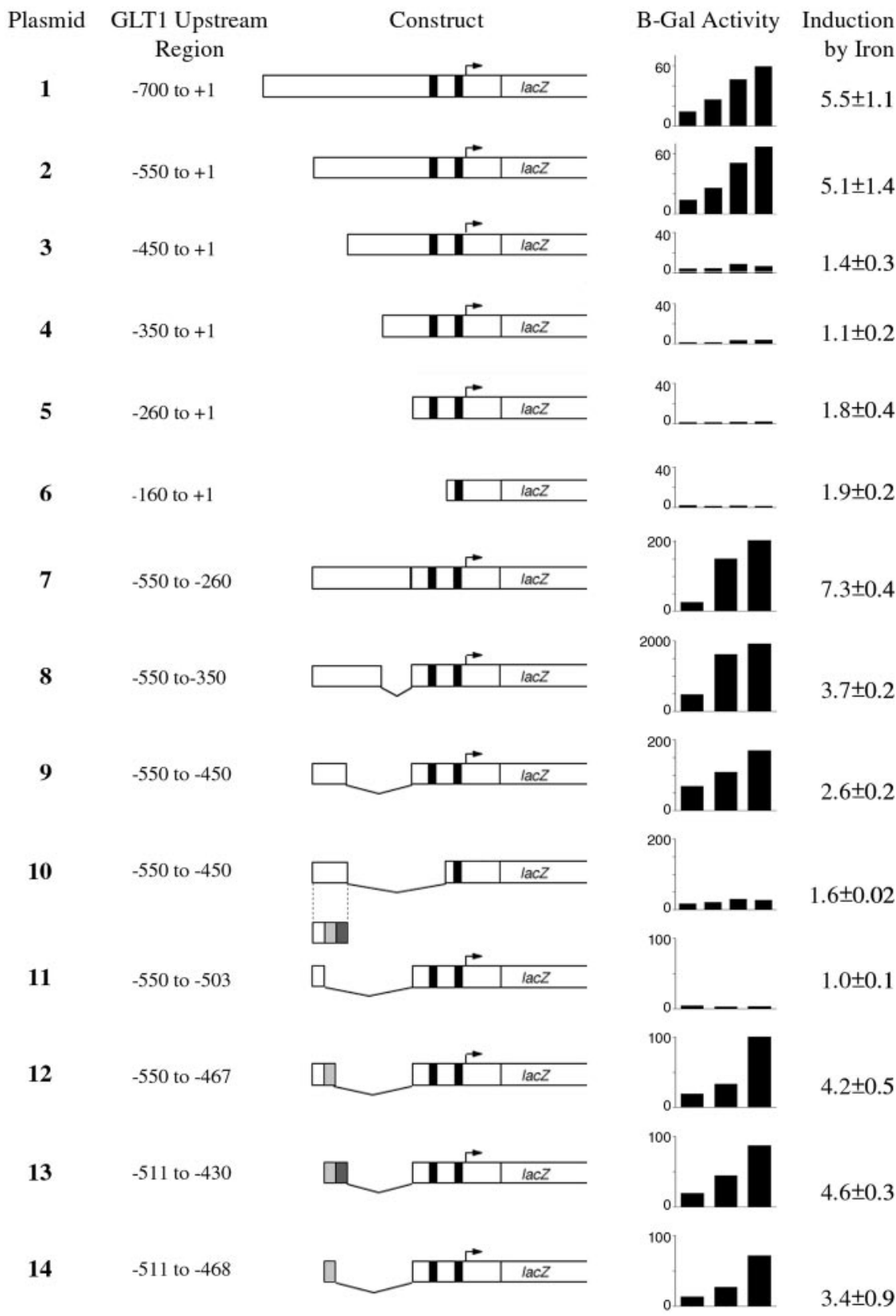

Figure 8. Identification of the iron-dependent activation sequence in the promoter of GLT1. Sequences upstream from the GLT1 open reading frame were fused to lac $Z$, and the resulting reporter constructs were transformed into the wild-type strain. Black bars indicate putative TATA boxes. Arrows indicate the transcription initiation site. $\beta$-Galactosidase activity was measured in lysates from cells grown in 5,20,100, and $500 \mu \mathrm{M}$ iron (plasmids 1-6 and 10) or 10,100, and 500 $\mu \mathrm{M}$ iron (plasmids 7-9 and 11-14), and the induction of activity from the lowest to highest iron concentration is indicated. Plasmids $1-6$, deletions from the $5^{\prime}$ end of the GLT1 promoter fused to the lacZ coding region. Plasmids 7-14, deletions from the $3^{\prime}$ end of the GLT1 promoter fused to the GLT1 TATA boxes of plasmid 5. Plasmids 11-14, shaded boxes refer to the $5^{\prime}$-most, center, and 3'-most third of the region between -550 and -450 Assays were performed in duplicate and each assay was repeated three times. Induction is reported with the average deviation.

base pair region from -511 to -468 contained the FeAS (Figure 8, plasmids 11-14). The GLT1 FeAS was not tested as a fusion to the CYC1 "minimal" promoter, because this minimal promoter exhibited iron-dependent activity in the absence of GLT1 sequences (J.H.T., unpublished observations).

The 44-base pair region that contained the FeAS was noted to contain a $\mathrm{CGGN}_{15} \mathrm{CCG}$ palindrome, and previous investigators have questioned whether this site might have a role in nitrogen-dependent regulation of GLT1 (Valenzuela et al., 1998). A CGG palindrome separated by a variable number of nucleotides constitutes a recognition site for a family of fungal transcription factors known as the binuclear Zn-cluster family (Todd and Andrianopoulos, 1997). We tested whether the CGG palindrome had a role in the irondependent regulation of GLT1 by mutating the half-sites individually and in combination, then measuring their ac- tivity as lacZ fusions (Table 1). Mutation of either half-site resulted in a significant loss of iron-dependent $\beta$-galactosidase activity, and mutation of both half-sites resulted in a near total loss of activity, indicating a role of the CGG palindromic sequences in the iron-dependent regulation of GLT1.

\section{DISCUSSION}

A set of genes under the control of Aft1p is actively transcribed during growth in an iron-poor environment, and the products of these genes function in the acquisition of iron, mobilization of intracellular iron stores, sequestration of other metals, and uptake of biotin. The processes of biotin uptake and biosynthesis were reciprocally regulated by iron, with uptake being activated when iron was scarce and biosynthesis being activated when iron was abundant. The 


\begin{tabular}{|c|c|c|c|}
\hline \multirow[b]{2}{*}{ Sequence } & \multicolumn{3}{|c|}{$\begin{array}{c}\beta \text {-Galactosidase } \\
\text { activity }\end{array}$} \\
\hline & $\begin{array}{l}\text { Low } \\
\text { Fe }\end{array}$ & $\begin{array}{l}\text { High } \\
\text { Fe }\end{array}$ & Ratio \\
\hline -533 GCGCAAATTTGGTCCTAATACACTTCGGTTTTAATGCGTCAATCCGATTGGCTCCGATAAGCTTTT -467 & 30.7 & 129.8 & 4.3 \\
\hline -533 GCGCAAATTTGGTCCTAATACACTTCAATTTTAATGCGTCAATCCGATTGGCTCCGATAAGCTTTT -467 & 24.2 & 43.3 & 1.8 \\
\hline 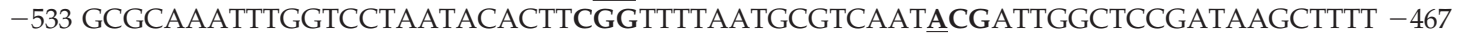 & 5.7 & 19.5 & 3.4 \\
\hline 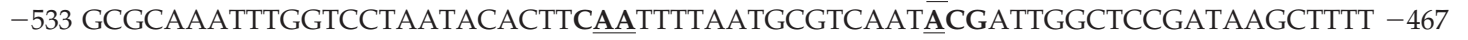 & 4.8 & 10.3 & 2.1 \\
\hline
\end{tabular}

Sequences shown were fused to plasmid 3 (see Figure 8). Nucleotides in bold form the CGG palindrome. Mutated residues are underlined.

effect of these changes in transcription was to transfer the essential process of biotin accumulation to an iron independent system when iron was scarce, thereby allowing the cell to conserve iron. A similar phenomenon was observed in the regulation of glutamate synthesis. When iron was scarce, GLT1 transcription was low, and glutamate biosynthesis was accomplished by the iron-independent activities of GDH1 and GDH3. When iron was abundant, GLT1 transcription was high, and glutamate was synthesized from glutamine and $\alpha$-ketoglutarate. Iron depletion activated genes involved in the uptake of alternative nitrogen sources and the metabolism of amino acids, whereas iron enrichment activated genes involved in purine synthesis. These changes may have occurred in response to changes in glutamate synthase activity. The transcriptional remodeling described here has the effect of shutting off nonessential metabolic pathways that consume iron during periods of iron deprivation. This suggests that the cell does not allow all irondependent pathways to become less active during iron deprivation, but rather the cell undergoes a transcriptional remodeling to allow the limited remaining iron to be selectively used in essential iron-requiring processes. These essential processes, such as the synthesis of deoxyribonucleotides, ergosterol, and long chain fatty acids, were not found to be regulated at the mRNA level by the alterations in iron described here.

In E. coli, iron deprivation results in the down-regulation of three iron-sulfur cluster-containing enzymes of the tricarboxylic acid cycle, succinate dehydrogenase ( $s d h C D A B)$, aconitase $(a c n A)$, and fumarase (fumA), as well as the Fedependent superoxide dismutase $(\operatorname{sod} B)$, although the homologous enzymes encoded by $a c n B$ and $f u m B$ are not regulated by iron. This regulation occurs through the activities of the small RNA RyhB, which may destabilize the RNAs transcribed from these loci (Masse and Gottesman, 2002). The microarrays that are reported in this study indicated that the iron-sulfur cluster enzymes of the tricarboxylic acid cycle (Sdh2p, Aco1p, and Fum1p) or of other amino acid biosynthetic pathways (Leu1p and Lys4) or Rli1p were not regulated by iron at the transcriptional level, neither were the enzymes involved in heme biosynthesis. However, these experiments were performed using a relatively mild degree of iron deprivation, and additional iron-dependent pathways may be down-regulated by more severe iron deprivation.

Heme is an enzyme cofactor that also acts in the transcriptional regulation of heme-dependent genes. Heme, acting through the HAP family of transcription factors, can induce the expression of a number of genes involved in respiration and aerobic growth, and several of these gene products require heme as a cofactor (Zhang and Hach, 1999). The role of heme in the regulation of transcription may be mainly as an indicator of oxygen levels, as heme synthesis is an oxygen-dependent process and these pathways are induced during aerobic metabolism (Kwast et al., 1998). However, heme-dependent transcription may also be affected by the availability of iron. Respiration and oxidative phosphorylation require the expression of iron-rich respiratory complexes and yeast exhibit an increased requirement for iron when forced to rely on respiration for energy production. Recent work indicates that transcription of the respiratory cytochrome Cyc1p is repressed during iron deprivation, and this transcriptional repression is due in part to the degradation of regulatory pools of heme by the Aft1p target gene, HMX1 (Protchenko and Philpott, 2003). Furthermore, transcription of HEM15 is also repressed by iron deprivation (Lesuisse et al., 2003). Thus, iron deprivation may indirectly repress the expression of heme-dependent metabolic pathways.

Metabolic pathways are frequently regulated at the transcriptional level by both substrates that are consumed in the pathway and by the products of the pathway. For example, galactose can activate the expression of a number of genes involved in galactose utilization through the Gal4p transcription factor (Johnston and Carlson, 1992), whereas glutamine can repress the transcription of glutamine synthetase through Gln3p (Magasanik, 1992) and adenine can repress the transcription of genes in the purine biosynthetic pathway through Bas1p and Bas2p (Daignan-Fornier and Fink, 1992). More complex modes of regulation of metabolic pathways also operate in yeast. The transcriptional control of tricarboxylic acid cycle genes shifts from the HAP transcription factors to the heterodimeric Rtg1/Rtg2 transcription factor when mitochondrial function is impaired (Liu and Butow, 1999). Here, we have described a mode of regulation in which the availability of a cofactor, iron, can activate, directly or indirectly, the expression of pathways that are dependent on iron-containing prosthetic groups.

The iron-dependent transcriptional activation of GLT1 required sequences that consisted of a CGG inverted repeat (a palindrome) that was separated by 15 nucleotides. This sequence is similar to the DNA binding sites that have been characterized for transcription factors of the binuclear zinc cluster family. Members of this fungalspecific family of transcription factors contain a characteristic $\mathrm{Cys}_{2} \mathrm{CysX}_{6} \mathrm{Cys}_{5-16} \mathrm{Cys}_{2} \mathrm{Cys}_{6-8} \mathrm{Cys}$ motif in the DNA binding domain that coordinates two zinc atoms (Todd and Andrianopoulos, 1997). These factors bind as homodimers to inverted, direct, or everted repeats of trinucleotide sequences, especially CGG, that are separated by a variable but defined number of nucleotides. Members of this family include Gal4p and Hap1p, and 
inspection of the genome of $S$. cerevisiae has revealed a total of 54 potential members of this gene family, many of which remain uncharacterized (Akache et al., 2001). Although the upstream regions of the BIO genes do not contain CGG palindromes identical to that of GLT1, they may be regulated by the same or similar transcription factors, as some diversity in the sequence of the terminal repeats occurs.

\section{ACKNOWLEDGMENTS}

We thank Jerry Kaplan and Alan Hinnebusch for generously providing plasmids, Claude Alban for generously sharing reagents, Juergen Stolz for sharing data before publication, and Jerry Kaplan for critically reading the manuscript.

\section{REFERENCES}

Adams, A., Gottschling, D.E., Kaiser, C.A., and Stearns, T. (1997). Methods in Yeast Genetics, Cold Spring Harbor, NY: Cold Spring Harbor Laboratory Press.

Akache, B., Wu, K., and Turcotte, B. (2001). Phenotypic analysis of genes encoding yeast zinc cluster proteins. Nucleic Acids Res. 29, 2181-2190.

Askwith, C., Eide, D., Van Ho, A., Bernard, P.S., Li, L., Davis-Kaplan, S., Sipe, D.M., and Kaplan, J. (1994). The FET3 gene of S. cerevisiae encodes a multicopper oxidase required for ferrous iron uptake. Cell 76, 403-410.

Blaiseau, P.L., Lesuisse, E., and Camadro, J.M. (2001). Aft2p, a novel ironregulated transcription activator that modulates, with Aft1p, intracellular iron use and resistance to oxidative stress in yeast, J. Biol. Chem. 276, 34221-34226.

Conklin, D.S., McMaster, J.A., Culbertson, M.R., and Kung, C. (1992). COT1, a gene involved in cobalt accumulation in Saccharomyces cerevisiae. Mol. Cell Biol. 12, 3678-3688.

Curti, B., Vanoni, M.A., Verzotti, E., and Zanetti, G. (1996). Glutamate synthase: a complex iron-sulphur flavoprotein. Biochem. Soc. Trans. 24, 95-99.

Daignan-Fornier, B., and Fink, G.R. (1992). Coregulation of purine and histidine biosynthesis by the transcriptional activators BAS1 and BAS2. Proc. Natl. Acad. Sci. USA 89, 6746-6750.

Dancis, A., Klausner, R.D., Hinnebusch, A.G., and Barriocanal, J.G. (1990). Genetic evidence that ferric reductase is required for iron uptake in Saccharomyces cerevisiae. Mol. Cell Biol. 10, 2294-2301.

Denis, V., and Daignan-Fornier, B. (1998). Synthesis of glutamine, glycine and 10 -formyl tetrahydrofolate is coregulated with purine biosynthesis in Saccharomyces cerevisiae. Mol. Gen. Genet. 259, 246-255.

DeRisi, J.L., Iyer, V.R., and Brown, P.O. (1997). Exploring the metabolic and genetic control of gene expression on a genomic scale. Science 278, 680-686.

Doherty, D. (1970). L-Glutamate dehydrogenases. Methods Enzymol. 17, 850856.

Foury, F., and Talibi, D. (2001). Mitochondrial control of iron homeostasis. A genome wide analysis of gene expression in a yeast frataxin-deficient strain. J. Biol. Chem. 276, 7762-7768.

Georgatsou, E., and Alexandraki, D. (1994). Two distinctly regulated genes are required for ferric reduction, the first step of iron uptake in Saccharomyces cerevisiae. Mol. Cell Biol. 14, 3065-3073.

Guarente, L., and Ptashne, M. (1981). Fusion of Escherichia coli lacZ to the cytochrome c gene of Saccharomyces cerevisiae. Proc. Natl. Acad. Sci. USA 78, 2199-2203.

Heymann, P., Ernst, J.F., and Winkelmann, G. (1999). Identification of a fungal triacetylfusarinine C siderophore transport gene (TAF1) in Saccharomyces cerevisiae as a member of the major facilitator superfamily. Biometals 12, 301-306.

Heymann, P., Ernst, J.F., and Winkelmann, G. (2000a). A gene of the major facilitator superfamily encodes a transporter for enterobactin (Enb1p) in Saccharomyces cerevisiae. Biometals 13, 65-72.

Heymann, P., Ernst, J.F., and Winkelmann, G. (2000b). Identification and substrate specificity of a ferrichrome-type siderophore transporter (Arn1p) in Saccharomyces cerevisiae. FEMS Microbiol. Lett. 186, 221-227.

Johnston, M., and Carlson, M. (1992). Regulation of carbon and phosphate utilization. In: The Molecular and Cellular Biology of the Yeast Saccharomyces, ed. E.W. Jones, J.R. Pringle, and J.R. Broach, Plainview, NY: Cold Spring Harbor Laboratory Press, 193-281.
Kwast, K.E., Burke, P.V., and Poyton, R.O. (1998). Oxygen sensing and the transcriptional regulation of oxygen-responsive genes in yeast. J. Exp. Biol $201,1177-1195$

Lesuisse, E., Santos, R., Matzanke, B.F., Knight, S.A., Camadro, J.M., and Dancis, A. (2003). Iron use for haeme synthesis is under control of the yeast frataxin homologue (Yfh1). Hum. Mol. Genet. 12, 879-889.

Lesuisse, E., Simon-Casteras, M., and Labbe, P. (1998). Siderophore-mediated iron uptake in Saccharomyces cerevisiae: the SIT1 gene encodes a ferrioxamine B permease that belongs to the major facilitator superfamily. Microbiology 144, 3455-3462.

Li, L., and Kaplan, J. (1998). Defects in the yeast high affinity iron transport system result in increased metal sensitivity because of the increased expression of transporters with a broad transition metal specificity. J. Biol. Chem. 273, 22181-22187.

Lin, S.J., Pufahl, R.A., Dancis, A., O’Halloran, T.V., and Culotta, V.C. (1997) A role for the Saccharomyces cerevisiae ATX1 gene in copper trafficking and iron transport. J. Biol. Chem. 272, 9215-9220.

Liu, Z., and Butow, R.A. (1999). A transcriptional switch in the expression of yeast tricarboxylic acid cycle genes in response to a reduction or loss of respiratory function. Mol. Cell Biol. 19, 6720-6728.

Ma, Q., and Herschman, H.R. (1995). The yeast homologue YTIS11, of the mammalian TIS11 gene family is a non-essential, glucose repressible gene. Oncogene 10, 487-494.

MacDiarmid, C.W., Gaither, L.A., and Eide, D. (2000). Zinc transporters that regulate vacuolar zinc storage in Saccharomyces cerevisiae. EMBO J. 19, 28452855

Magasanik, B. (1992). Regulation of nitrogen utilization. In: The Molecular and Cellular Biology of the Yeast Saccharomyces, ed. E.W. Jones, J.R. Pringle, and J.R. Broach, Plainview, NY: Cold Spring Harbor Laboratory Press, 283317.

Mantsala, P., and Zalkin, H. (1984). Glutamine nucleotide sequence of Saccharomyces cerevisiae ADE4 encoding phosphoribosylpyrophosphate amidotransferase. J. Biol. Chem. 259, 8478-8484.

Marquet, A., Bui, B.T., and Florentin, D. (2001). Biosynthesis of biotin and lipoic acid. Vitam. Horm. 61, 51-101.

Martins, L.J., Jensen, L.T., Simon, J.R., Keller, G.L., Winge, D.R., and Simons, J.R. (1998). Metalloregulation of FRE1 and FRE2 homologs in Saccharomyces cerevisiae [published erratum appears in J. Biol. Chem. 1998 Nov 6;273(45): 30056]. J. Biol. Chem. 273, 23716-23721.

Masse, E., and Gottesman, S. (2002). A small RNA regulates the expression of genes involved in iron metabolism in Escherichia coli. Proc. Natl. Acad. Sci. USA 99, 4620-4625.

Mitchell, A.P., and Magasanik, B. (1983). Purification and properties of glutamine synthetase from Saccharomyces cerevisiae. J. Biol. Chem. 258, 119-124.

Ollagnier-deChoudens, S., and Fontecave, M. (1999). The lipoate synthase from Escherichia coli is an iron-sulfur protein. FEBS Lett. 453, 25-28.

Philpott, C.C., Rashford, J., Yamaguchi-Iwai, Y., Rouault, T.A., Dancis, A., and Klausner, R.D. (1998). Cell-cycle arrest and inhibition of G1 cyclin translation by iron in AFT1-1(up) yeast. EMBO J. 17, 5026-5036.

Portnoy, M.E., Jensen, L.T., and Culotta, V.C. (2002). The distinct methods by which manganese and iron regulate the Nramp transporters in yeast. Biochem. J. 362, 119-124.

Portnoy, M.E., Liu, X.F., and Culotta, V.C. (2000). Saccharomyces cerevisiae expresses three functionally distinct homologues of the nramp family of metal transporters. Mol. Cell Biol. 20, 7893-7902.

Protchenko, O., Ferea, T., Rashford, J., Tiedeman, J., Brown, P.O., Botstein, D. and Philpott, C.C. (2001). Three cell wall mannoproteins facilitate the uptake of iron in Saccharomyces cerevisiae. J. Biol. Chem. 276, 49244-49250.

Protchenko, O., and Philpott, C.C. (2003). Regulation of intracellular heme levels by HMX1, a homologue of heme oxygenase, in Saccharomyces cerevisiae. J. Biol. Chem. 278, 36582-36587.

Roon, R.J., Even, H.L., and Larimore, F. (1974). Glutamate synthase: properties of the reduced nicotinamide adenine dinucleotide-dependent enzyme from Saccharomyces cerevisiae. J. Bacteriol. 118, 89-95.

Rutherford, J.C., Jaron, S., Ray, E., Brown, P.O., and Winge, D.R. (2001). A second iron-regulatory system in yeast independent of Aft1p. Proc. Natl. Acad. Sci. USA 98, 14322-14327.

Rutherford, J.C., Jaron, S., and Winge, D.R. (2003). Aft1p and Aft2p mediate iron-responsive gene expression in yeast through related promoter elements, J. Biol. Chem. 19, 19. 
Sherman, F. (1991). Getting started with yeast. In: Guide to Yeast Genetics and Molecular Biology, ed. C. Guthrie and G. Fink, New York: Academic Press, $3-20$

Stadler, J.A., and Schweyen, R.J. (2002). The yeast iron regulon is induced upon cobalt stress and crucial for cobalt tolerance. J. Biol. Chem. 277, 3964939654.

Stearman, R., Dancis, A., and Klausner, R.D. (1998). YIpDCE1 - an integrating plasmid for dual constitutive expression in yeast. Gene 212, 197-202.

Stearman, R., Yuan, D.S., Yamaguchi-Iwai, Y., Klausner, R.D., and Dancis, A. (1996). A permease-oxidase complex involved in high-affinity iron uptake in yeast [see comments]. Science 271, 1552-1557.

Stolz, J., Hoja, U., Meier, S., Sauer, N., and Schweizer, E. (1999). Identification of the plasma membrane $\mathrm{H}+$-biotin symporter of Saccharomyces cerevisiae by rescue of a fatty acid-auxotrophic mutant. J. Biol. Chem. 274, 18741-18746.

Thompson, M.J., Lai, W.S., Taylor, G.A., and Blackshear, P.J. (1996). Cloning and characterization of two yeast genes encoding members of the $\mathrm{CCCH}$ class of zinc finger proteins: zinc finger-mediated impairment of cell growth. Gene $174,225-233$

Todd, R.B., and Andrianopoulos, A. (1997). Evolution of a fungal regulatory gene family: the $\mathrm{Zn}(\mathrm{II}) 2 \mathrm{Cys} 6$ binuclear cluster DNA binding motif. Fungal Genet. Biol. 21, 388-405.

Urbanowski, J.L., and Piper, R.C. (1999). The iron transporter Fth1p forms a complex with the Fet5 iron oxidase and resides on the vacuolar membrane. J. Biol. Chem. 274, 38061-38070.

Valenzuela, L., Ballario, P., Aranda, C., Filetici, P., and Gonzalez, A. (1998) Regulation of expression of GLT1, the gene encoding glutamate synthase in Saccharomyces cerevisiae. J. Bacteriol. 180, 3533-3540.
Yamaguchi-Iwai, Y., Dancis, A., and Klausner, R.D. (1995). AFT 1, a mediator of iron regulated transcriptional control in Saccharomyces cerevisiae. EMBO J. 14, 1231-1239.

Yamaguchi-Iwai, Y., Stearman, R., Dancis, A., and Klausner, R.D. (1996). Iron-regulated DNA binding by the AFT1 protein controls the iron regulon in yeast, EMBO J. 15, 3377-3384.

Yamaguchi-Iwai, Y., Ueta, R., Fukunaka, A., and Sasaki, R. (2002). Subcellular localization of Aft1 transcription factor responds to iron status in Saccharomyces cerevisiae. J. Biol. Chem. 277, 18914-18918.

Yuan, D.S., Stearman, R., Dancis, A., Dunn, T., Beeler, T., and Klausner, R.D (1995). The Menkes/Wilson disease gene homologue in yeast provides coppe to a ceruloplasmin-like oxidase required for iron uptake. Proc. Natl. Acad. Sci. USA 92, 2632-2636.

Yun, C.W., Bauler, M., Moore, R.E., Klebba, P.E., and Philpott, C.C. (2001) The role of the FRE family of plasma membrane reductases in the uptake of siderophore-iron in Saccharomyces cerevisiae. J. Biol. Chem. 276, 10218-10223.

Yun, C.W., Ferea, T., Rashford, J., Ardon, O., Brown, P.O., Botstein, D., Kaplan, J., and Philpott, C.C. (2000a). Desferrioxamine-mediated iron uptake in Saccharomyces cerevisiae. Evidence for two pathways of iron uptake. J. Biol. Chem. 275, 10709-10715.

Yun, C.W., Tiedeman, J.S., Moore, R.E., and Philpott, C.C. (2000b). Siderophore-iron uptake in Saccharomyces cerevisiae. Identification of ferrichrome and fusarinine transporters. J. Biol. Chem. 275, 16354-9.

Zhang, L., and Hach, A. (1999). Molecular mechanism of heme signaling in yeast: the transcriptional activator Hap1 serves as the key mediator. Cell Mol. Life Sci. 56, 415-426. 